\title{
Classificação taxonômica de categorias de serviços públicos para aplicações digitais
}

\author{
Georgia C. Pereira ${ }^{1}$, Ingrid T. Monteiro ${ }^{2}$, Davi R. Vasconcelos ${ }^{2}$, Leonara \\ Braz $^{2}$, Carlos H. C. Silva ${ }^{1}$ \\ 'Instituto Universidade Virtual - Fortaleza, CE - Brasil \\ ${ }^{2}$ Campus de Quixadá - Quixadá, CE - Brasil \\ Universidade Federal do Ceará (UFC) \\ georgia@virtual.ufc.br, ingrideufc.br, \\ \{daviromero, leonarabraz\}@insightlab.ufc.br, carlos.hcs1998@gmail.com
}

\begin{abstract}
This paper presents a model for standardizing terminologies (taxonomy) for categories of public services offered in digital applications. Based on a benchmarking of web portals and mobile applications from Brazilian federal units, there was a need for a hierarchy of information and a standardization of the terminologies used in order to allow the construction of clearer interfaces and allowing more qualified access for citizens services provided. The proposed categories are based on a functional association.
\end{abstract}

Resumo. O presente trabalho apresenta um modelo de padronização de terminologias (taxonomia) para categorias de serviços públicos ofertados em aplicações digitais. Com base em levantamento de portais web e aplicações mobile de unidades federativas brasileiras, constatou-se a necessidade de uma hierarquização das informações e uma padronização das terminologias empregadas de modo a permitir a construção de interfaces mais claras e que permitam um acesso mais qualificado dos cidadãos aos serviços prestados. As categorias propostas têm como base uma associação funcional.

\section{Introdução}

O mundo vive um acelerado processo de transformação digital. Cada vez mais processos da vida cotidiana passam por uma mediação de Tecnologias Digitais da Informação e da Comunicação (TDICs). Nas últimas duas décadas, há no Brasil um crescente movimento de governos digitalizando seus serviços como parte de uma estratégia para atender de maneira mais qualificada seus cidadãos. Essa digitalização traz benefícios e desafios para o setor público, que precisa levar em consideração as reais necessidades da população, negócios e comunidades e quais as formas mais eficientes de atendê-las [OECD 2014].

Com a aceleração do movimento de transformação digital por parte dos governos na última década, há uma necessidade cada vez maior de se discutir a qualidade das interfaces disponibilizadas aos cidadãos [Brasil 2018]. Um problema encontrado a partir de um levantamento diagnóstico está na falta de padronização acerca das terminologias utilizadas para a oferta de serviços públicos digitais.

A partir do benchmarking feito com 25 portais web e 9 aplicativos de unidades federativas brasileiras, identificou-se uma enorme variedade de nomenclaturas aplicadas 
para um mesmo serviço. Acredita-se que isso possa ocorrer devido ao modo como essas interfaces têm sido construídas, autonomamente, e sem diretrizes que balizam suas proposições. Essa falta de consistência mostra-se problemática quando se observa o cenário de governança digital desejado em nível nacional, cujos marcos regulatórios preveem padronização e possibilidade de interoperabilidade de sistemas até 2022 [Brasil 2020].

A questão ganha contornos ainda mais relevantes a serem destacados quando se percebe a pouca oferta de diretrizes nacionais acerca das terminologias a serem empregadas para a apresentação desses serviços ao público e sua organização. Em 2004, iniciaram-se os trabalhos em direção à construção do "Vocabulário Controlado do Governo Eletrônico", no âmbito do governo federal, mas esta é uma iniciativa ainda pouco conhecida e adotada nos governos estaduais [Brasil 2016].

Dessa forma, visando um aprimoramento das aplicações de serviços públicos digitais, procedemos um estudo das categorias apresentadas na oferta dos serviços em 25 portais web e 9 aplicativos móveis de unidades federativas brasileiras. A presente pesquisa coletou, tabulou e analisou os dados de nomenclaturas das categorias coletadas nestes ambientes. Como resultado, propõe-se uma taxonomia padrão para apresentação de categorias de serviços públicos digitais, com critérios de organização mais bem definidos. A terminologia adotada baseia-se em linguagem simples, ou seja, uma linguagem mais clara e menos burocrática voltada para o cidadão [Fischer et al. 2019]. A taxonomia foi desenvolvida para auxiliar no contexto dos serviços do governo do Estado do Ceará, mas acredita-se no seu potencial de aplicação nos serviços públicos de outros estados e outras esferas administrativas.

\section{Usabilidade e Taxonomia}

Ao focar nos critérios de qualidade de uso e no design centrado em seres humanos, podese desenvolver produtos que atendam de maneira mais eficiente às necessidades daqueles que precisam deles, levando em consideração não somente fatores objetivos, mas também aspectos emocionais e subjetivos que impactam na interação [Barbosa e Silva 2010]. Fatores como apropriação reconhecível, inteligibilidade, acessibilidade, operabilidade, estética da interface com o usuário e proteção contra o erro são alguns pontos a serem levados em questão quando se pensa na qualidade de uso de uma aplicação. [ISO/IEC 25010 2011]

Quando observado o cenário das aplicações de serviços públicos digitais brasileiros e a falta de consistência e padronização do ponto de vista da apresentação das categorias de serviços, enxergamos aí um problema a ser investigado do ponto de vista da usabilidade e da arquitetura da informação, uma vez que os desdobramentos da questão têm potencial de impacto para todos os envolvidos na cadeia: desenvolvedores, governos e cidadãos. Terminologias confusas, ambíguas e pouco claras podem impactar numa maior resistência à adoção das soluções tecnológicas envolvidas ou abandono do uso.

Taxonomia pode ser considerada como uma maneira de facilitar a organização de informações e sua apresentação. A partir da construção de uma taxonomia é possível estabelecer regras de classificação para conteúdos, possibilitando um acesso mais facilitado e otimizado por parte dos usuários [Martínez et al. 2004]. Quando se trabalha com um volume diverso de informações, é necessária uma organização estruturante desses dados para que seu acesso seja mais efetivo.

Taxonomia é apontado por Rosenfeld, Morville e Arango (2015) como sinônimo para esquema de classificação, onde se tem um arranjo entre termos escolhidos. Para 
Hedden (2010), taxonomia pode ser entendida num sentido amplo com uma estrutura de organização de conhecimento. Ao organizar as informações em arranjos semânticos e hierárquicos é possível estabelecer padrões de disponibilização de informação, de classificação de novas informações, de modo a facilitar seu acesso. A adoção de um vocabulário controlado traz ainda benefícios em termos de consistência [Hedden 2010].

Ao pensar sua adoção no campo de estudos de usabilidade e experiência do usuário, é possível destacar seu possível impacto do ponto de vista da comunicabilidade das interfaces, na encontrabilidade e memorabilidade. Para Rosenfeld, Morville e Arango (2015, p.25), "encontrabilidade é um fator crítico de sucesso para a usabilidade geral. Se os usuários não encontram o que precisam a partir de uma combinação de navegação, busca e fazendo perguntas, então o sistema falhou."

Ao trabalhar com uma padronização de terminologias, busca-se ampliar a clareza, simplicidade da linguagem e facilidade de associação dos termos com as tarefas a serem executadas. "O objetivo de um vocabulário controlado é garantir consistência na aplicação de termos de índice, tags ou rótulos para evitar ambigüidade e a omissão de informações se o termo de pesquisa 'errado' for usado.” [Hedden 2010, p.36]. Pensando nisso, em termos de oferta de serviços públicos digitais, pode-se supor como resultante uma maior qualidade no uso dessas aplicações, além da consistência entre plataformas, permitindo uma adoção mais facilitada dessas interfaces por parte dos cidadãos usuários [PwC EU Services 2019].

Diferentes entes da federação têm adotado nomenclaturas diversas para um mesmo conjunto de serviços, havendo, inclusive, a ocorrência de estados com divergência de nomenclaturas até mesmo entre suas aplicações web e mobile. Dentre outros fatores, pode-se inferir que essa questão se dá pela falta de orientações claras ou modelizantes que norteiem os esforços dos agentes públicos na execução de soluções de governo digital.

Tem havido nos últimos anos um avanço na literatura acerca do desenvolvimento dessas aplicações, mas há pouco sendo discutido no que se refere à taxonomia e a sua importância para a área. Importante ressaltar que a adoção de uma rotulação padrão permite estruturar a disposição da informação, os potenciais de expansão das interfaces e um projeto de desenvolvimento centrado no usuário. Nesse sentido, há iniciativas de padronização dos termos utilizados para serviços públicos como a apresentada pela União Europeia, cujo relatório destaca uma taxonomia comum que pode permitir uma oferta de serviços similar, bem como auxiliar na avaliação de serviços entre estados, além de facilitar o acesso. [PwC EU Services 2019]

\section{Metodologia}

Este estudo foi realizado como parte integrante do projeto de aceleração da transformação digital para o estado do Ceará, no eixo temático de experiência do usuário. O estudo, em particular, teve como objetivo compreender de que maneira informações acerca da oferta dos serviços públicos estão sendo apresentadas aos cidadãos em portais e aplicativos governamentais brasileiros e de que modo essas informações podem ser requalificadas visando uma melhora na experiência de uso e encontrabilidade de informações.

Para tanto, como modo de compreender o cenário de maneira diagnóstica e analítica, realizou-se um levantamento com a metodologia de benchmarking nos portais web e aplicativos dos governos estaduais e do Distrito Federal. Um benchmarking consiste em coletar e comparar práticas de um determinado segmento, com o objetivo de aprimoramento [Komninos 2008]. Realizar um levantamento dessa natureza nos permite 
fazer um estudo comparativo do que está sendo praticado no setor. Com seu resultado, também se objetiva dados e parâmetros que auxiliem na tomada de decisão para o desenvolvimento e/ou melhoria de aplicações de serviços públicos digitais.

A busca por portais foi realizada por meio do buscador Google, com o nome das unidades federativas acompanhado do termo "gov". Ao ingressar em cada portal governamental, procurou-se observar como ocorria a oferta dos serviços governamentais. Na maioria dos casos, o governo disponibiliza um portal próprio diferente do portal oficial do governo. Assim, houve casos em que o portal de serviços foi analisado e em outros o portal geral do governo. Os aplicativos mobile foram obtidos a partir de busca na loja de aplicativos para dispositivos Android, a Play Store.

Dessa forma, o início dos trabalhos se deu pela realização de um mapeamento dos portais de serviços e aplicativos móveis que serviriam como base para a coleta de dados. A seguir, fez-se o registro das organizações de informações (capturas de telas) e tabulação das nomenclaturas das ofertas de serviços públicos apresentadas nas interfaces. Para a inclusão no levantamento, foram considerados os termos de categorias de serviços. Os dados foram coletados entre os meses de setembro e novembro de 2020. Foram levados em consideração os quantitativos de categorias de serviços ofertados, bem como os termos utilizados para se referir às categorias. O levantamento quantitativo permitiu identificar quais as categorias de serviços mais recorrentes na amostra, servindo de panorama empírico para a compreensão do estado de oferta de serviços públicos digitais pelos estados brasileiros e o Distrito Federal. Foi possível ainda, dada a coleta visual de capturas de tela, fazer inferências acerca da organização dessas categorias e adequações de suas representações gráficas, a serem exploradas em estudos futuros.

Por categoria se entende aqui uma classe que agrupe serviços como uma parte importante para a organização dos conteúdos [Rosenfeld, Morville, Arango 2015]. Durante o registro, os dados colhidos foram agrupados por unidade federativa e separados por interface de ocorrência: se portal web ou aplicativo mobile. Após o período de coleta, todos os dados foram organizados em planilhas e procedeu-se uma análise de ocorrência de termos e organização de conjuntos semânticos agrupados por similaridade e homonimidade. Seguiu-se o procedimento de agrupamento de informações indicado pelos autores como modo de evitar interferências de outros aspectos do desenvolvimento.

Esse procedimento permitiu identificar padrões de tipologias de serviços que, mesmo apresentados com variações terminológicas nas interfaces, poderiam ser reunidos numa única rotulação padrão aplicável ao conjunto analisado [Hedden 2010]. Assim, foi possível apresentar um primeiro desenho de vocabulário controlado, observando a ocorrência de nomes de categorias homônimos, mas utilizados para designar conjuntos de serviços distintos. Essa etapa visou desfazer ambiguidades e ampliar o entendimento dos termos adotados.

Após essa checagem, passou-se à construção dos novos arranjos semânticos para as categorias, levando-se em consideração a necessidade de clareza e simplicidade da linguagem empregada na proposta de taxonomia. Outro critério adotado foi o de nomear as categorias a partir das funcionalidades relacionadas, não mais de acordo com os órgãos ou secretarias aos quais aqueles serviços estavam vinculados. Essas funcionalidades foram batizadas de descritores e objetivam nortear a necessidade de inclusão de futuros serviços nas categorias, garantindo uma classificação mais coerente. Possibilitam, ainda, a adoção do modelo por outras equipes de desenvolvimento para a organização de suas informações. 
O processo foi dividido em duas etapas: na primeira todas as categorias foram analisadas e classificadas; na segunda foi feito o refinamento da proposta de nomenclatura, considerando os serviços que se encaixavam nessas expressões.

\section{Resultados}

A partir do levantamento de portais web das 27 unidades federativas, observou-se que 25 deles disponibilizam o acesso a serviços governamentais organizados em categorias. Destes, apenas quatro não disponibilizam portais específicos para a oferta de serviços. Em relação aos aplicativos, foram analisados nove deles. A Tabela 1 apresenta os dados dos portais e aplicativos considerados na análise de categorias. Destacamos em negrito os estados que não disponibilizam um portal específico para oferta dos serviços; dessa forma, nesses estados destacados, foi analisado seu portal geral. Assim, 21 dos 25 portais analisados (não-negritos) são dedicados à oferta de serviços. Alagoas, curiosamente, não tem um portal governamental tradicional como todos os outros estados. Seu site oficial "https://alagoasdigital.al.gov.br/" é inteiramente focado em serviços, não apresentando conteúdos e estruturas comuns aos outros estados como apresentação de secretarias e órgãos do governo, notícias, informações sobre o(a) governador(a) etc.

De todos os estados, apenas Rio de Janeiro e São Paulo não tiveram seus portais analisados. No primeiro caso, não se identificou no portal oficial (http://www.rj.gov.br/), qualquer referência a serviços. Há uma opção de busca, mas que não apresentou resultados para os serviços testados, como, por exemplo, IPVA e Detran. Também não foi encontrado um portal dedicado a serviços do governo fluminense. Já para o estado de São Paulo, aparentemente, há um portal dedicado a serviços (http://www.cidadao.sp.gov.br/), mas ao se clicar na aba "Serviços" em busca das categorias de serviço, o link não funciona ${ }^{1}$.

Em relação aos aplicativos, observou-se que há casos em que o estado não disponibiliza um aplicativo centralizador de serviços, oferecendo vários aplicativos voltados a temas, secretarias ou serviços específicos, como por exemplo, aplicativos de Detran, de saúde ou voltados para servidores públicos. Houve ainda casos em que o aplicativo do governo não disponibilizava os serviços organizados em categorias, inviabilizando a análise, como é o caso do aplicativo cearense Ceará APP.

Tabela 1. Portais e aplicativos analisados

\begin{tabular}{l|l|l}
\hline \multicolumn{2}{l}{ Portal } & App \\
\hline AC & http://acre.gov.br/cidadao/ & \\
\hline AL & https://alagoasdigital.al.gov.br/ & \\
\hline AP & https://servicos.portal.ap.gov.br/ & \\
\hline AM & http://www.amazonas.am.gov.br/servicos/cidadao/ & \\
\hline BA & https://www.sacdigital.ba.gov.br/ & SAC Digital \\
\hline CE & https://cartadeservicos.ce.gov.br/ & \\
\hline DF & http://www.df.gov.br/category/servicos-2/ & e-GDF \\
\hline ES & https://guiadeservicos.es.gov.br/ & ES na Palma da Mão \\
\hline GO & https://www.go.gov.br/ & \\
\hline MA & https://www.ma.gov.br/ & \\
\hline MT & http://www.mt.gov.br/servicos & MT Cidadão
\end{tabular}

\footnotetext{
${ }^{1}$ Na verdade, menus, busca ou links para serviços diretos não funcionam. Só funcionam os links que levam para domínios externos, como para o site do DETRAN. Acesso realizado entre setembro/2020 e março/2021.
} 


\begin{tabular}{l|l|l}
\hline MS & https://www.cartasdeservicos.ms.gov.br/ & MS Digital \\
\hline MG & https://www.mg.gov.br/ & MG App - Cidadão \\
\hline PA & https://www.pa.gov.br/servicos & \\
\hline PB & https://portaldacidadania.pb.gov.br/ & Portal da Cidadania \\
\hline PR & https://www.pia.pr.gov.br/ & $\begin{array}{l}\text { PIÁ - Paraná Inteligência } \\
\text { Artificial }\end{array}$ \\
\hline PE & https://www.pecidadao.pe.gov.br/ & PE Cidadão \\
\hline PI & https://www.pi.gov.br/servicos-por-tema & \\
\hline RJ & - & \\
\hline RN & http://www.cidadao.rn.gov.br/ & \\
\hline RS & https://www.rs.gov.br/ & \\
\hline RO & http://www.rondonia.ro.gov.br/ & \\
\hline RR & http://portal.rr.gov.br/ & \\
\hline SC & https://www.sc.gov.br/servicos/ & \\
\hline SP & - & \\
\hline SE & https://www.ceac.se.gov.br/ & \\
\hline TO & https://servicos.to.gov.br/ & \\
\hline
\end{tabular}

Um aspecto curioso é a forma da URL dos portais. A maioria dos estados segue o formato "[sigla].gov.br" para o portal governamental oficial. As exceções foram os estados de Goiás e Rio Grande do Sul, que reservaram este formato para seus portais de serviço e utilizaram outro formato para o portal governamental (respectivamente, https://www.goias.gov.br/ e https://www.estado.rs.gov.br).

Para cada portal e aplicativo, coletamos todas as categorias de serviços apresentadas. No total foram $\mathbf{6 3 3}$ categorias listadas, 518 categorias referentes aos portais e 114 dos aplicativos. A Figura 1 mostra a quantidade de categorias presentes em cada portal web enquanto a Figura 2 apresenta a quantidade de categorias presentes em cada aplicativo.

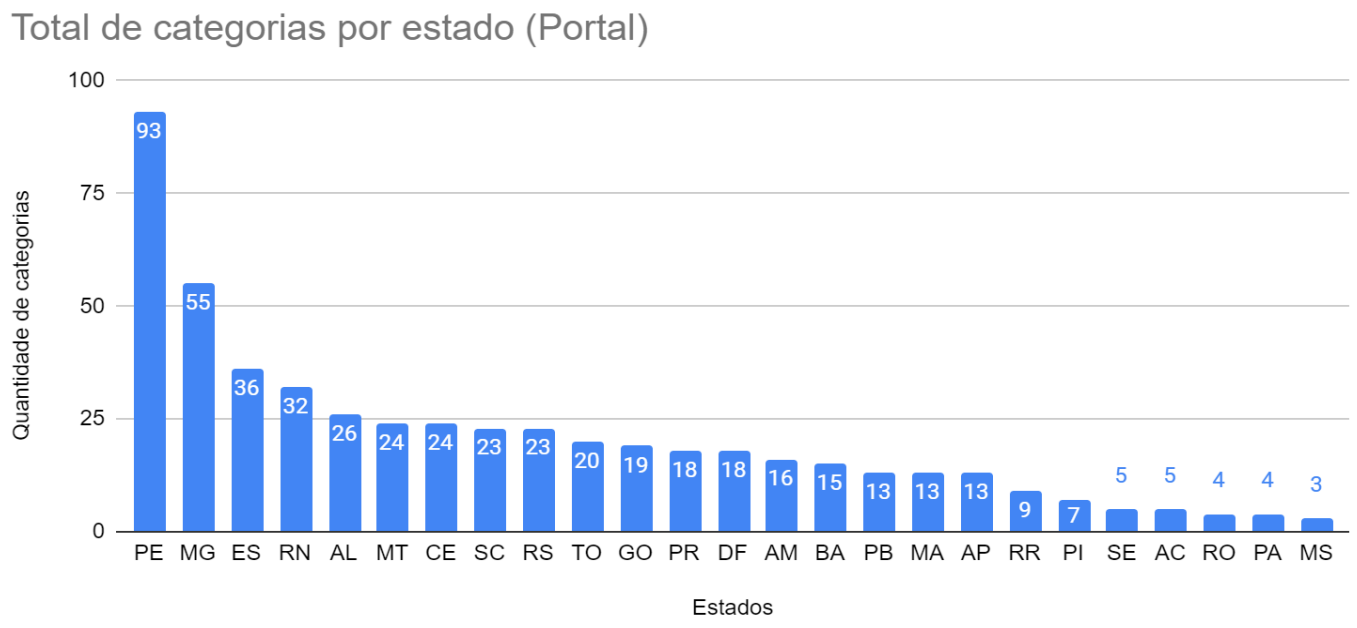

Figura 1 - Número de categorias por portal. Fonte - Informações extraídas dos portais governamentais das unidades federativas. Gráfico elaborado pelos autores (2021). 


\section{Total de categorias por estado (Apps)}

25

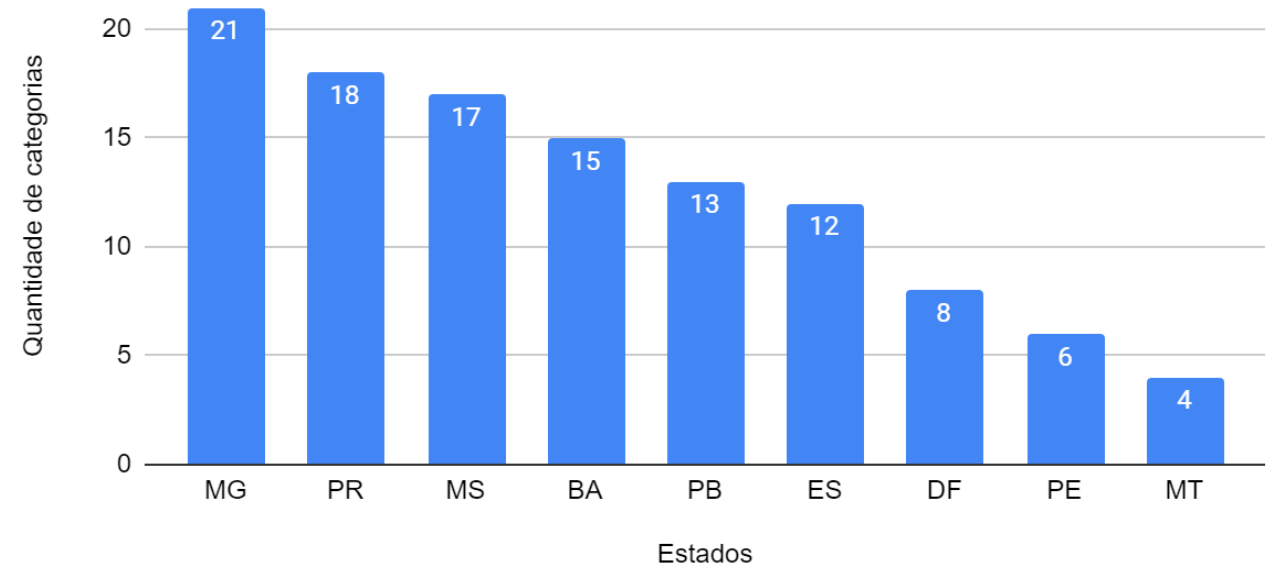

Figura 2 - Número de categorias por aplicativos. Fonte:Informações extraídas dos portais governamentais das Unidades Federativas. Gráfico elaborado pelos autores (2021).

A Figura 3 apresenta a nuvem de palavras criada a partir das nomenclaturas utilizadas nos portais. Nela, é possível visualizar os termos mais frequentes nas nomenclaturas das categorias dos portais e aplicativos. Observa-se que palavras como "Educação", "Saúde", "Social", "Habitação", "Segurança" têm destaque, todas relacionadas às funções básicas do estado na garantia dos direitos dos cidadãos. 


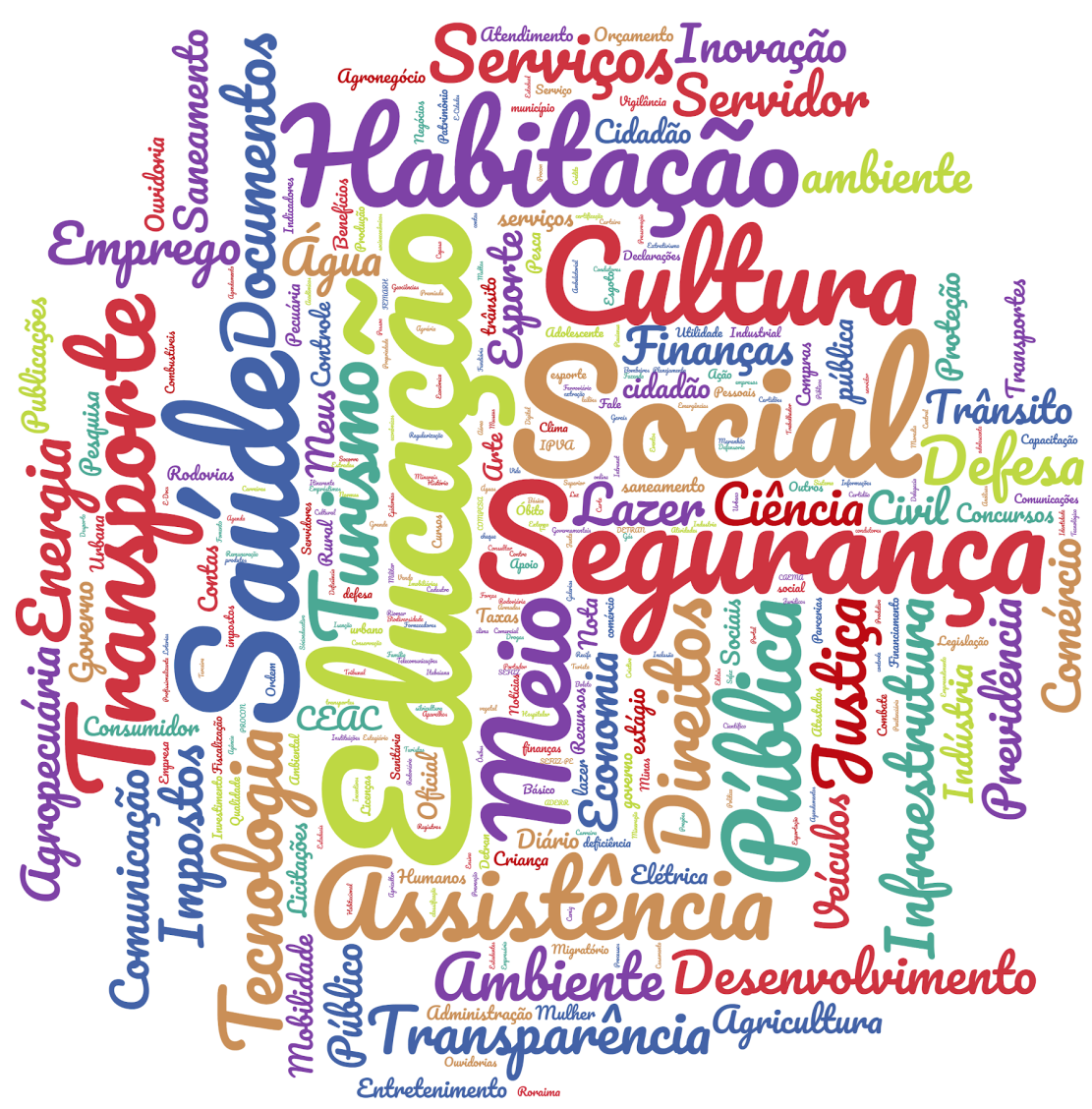

Figura 3 - Nuvem de Palavras - Fonte: Elaborada pelos autores (2021)

\section{Discussão}

Fazendo uma análise do agrupamento das categorias apresentadas nos portais e aplicativos, percebem-se problemas na organização dos serviços por categorias. O portal de Pernambuco apresenta diferentes categorias que poderiam ser agrupadas, pois tratam do mesmo serviço, como, por exemplo: "Energia" e "Energia elétrica", "Habitação" e "Habitação Rural", "Economia" e "Economia E Finanças". É importante destacar que alguns portais possuem 'categorias fantasmas', ou seja, que não possuem nenhum serviço ou conteúdo relacionados a elas. Exemplos de 'categorias fantasmas' foram encontradas nos portais de Pernambuco e Minas Gerais.

O portal de Minas Gerais usa a macrocategoria "Cidadão", entretanto categorias como: "Criança e adolescente", "Mulher" e "Terceira idade" também aparecem. Analisando os serviços ofertados em tais categorias, vê-se que eles poderiam ser agrupados em categorias como "Saúde" ou "Assistência Social", sem necessidade de se criar categorias que dividem o público "Cidadão" em categorias de gênero ou idade.

A fim de minimizar os problemas de taxonomia expostos, o presente trabalho propõe um esquema de taxonomia base para aplicação futura em um portal governamental. O objetivo é evitar o excesso de categorias gerado por redundância ou especificidade desnecessária, além de trazer mais funcionalidade à organização dos serviços nas categorias. Portanto, depois de catalogar todas as 633 categorias, criou-se uma nomenclatura padrão com 26 expressões, para agrupar categorias semelhantes.

A taxonomia foi desenvolvida a partir da análise de todas as categorias e serviços estudados nas unidades federativas, fazendo vínculo entre categorias/serviços 
semelhantes. Foram levados em consideração a natureza dos serviços oferecidos, a clareza da terminologia empregada, a recorrência do uso. Por exemplo, as categorias "Água", "Abastecimento", "Saneamento", "Água e esgoto" encontradas nos portais e apps foram todas agrupadas numa categoria padrão chamada "Água e saneamento".

A Tabela 2 apresenta as 26 expressões estabelecidas para agrupar as categorias de serviço encontradas durante a análise. A coluna "Categorias" informa a quantidade de nomes únicos que foram encontrados correspondentes à nomenclatura padrão. Por exemplo, a expressão "Gestão Pública" envolve 38 diferentes nomenclaturas, três das quais estão listadas na coluna "Exemplos".

A coluna "Ocorrências" lista o total de ocorrências relativas àquela expressão, ou seja, das 633 categorias classificadas, 53 correspondem a "Gestão Pública", 51, a "Ação Social e Cidadania" e assim por diante. Um número alto na coluna "Categorias" pode indicar dois fenômenos: ou que há uma grande variedade de serviços pertencente àquela categoria ou que há uma grande disparidade de nomes entre os estados. Um número alto na coluna "Ocorrências" indica que aquela categoria de serviços é muito comum nos serviços públicos estaduais.

Tabela 2. Categorias padrão

\begin{tabular}{|c|c|c|c|}
\hline Nomenclatura padrão & Categorias & Exemplos & Ocorrências \\
\hline Gestão Pública & 38 & $\begin{array}{l}\text { Servidor Público; Licitações; } \\
\text { Orçamento }\end{array}$ & 53 \\
\hline Ação Social e Cidadania & 36 & $\begin{array}{l}\text { Assistência Social; Direitos e } \\
\text { cidadania; Pessoas com } \\
\text { deficiência }\end{array}$ & 51 \\
\hline Empresas e Negócios & 35 & $\begin{array}{l}\text { Comércio e Serviços; } \\
\text { Produção Industrial; } \\
\text { Exportação }\end{array}$ & 40 \\
\hline Cultura, Esporte e Lazer & 21 & $\begin{array}{l}\text { Turismo e Lazer; Arte e } \\
\text { cultura; Eventos }\end{array}$ & 40 \\
\hline Educação & 18 & $\begin{array}{l}\text { Cursos e capacitação; } \\
\text { Estudantes; Educação } \\
\text { Superior }\end{array}$ & 39 \\
\hline Saúde & 12 & $\begin{array}{l}\text { Socorro e Emergência; } \\
\text { Coronavírus; } \\
\text { Combate A Drogas }\end{array}$ & 35 \\
\hline Segurança Pública & 14 & $\begin{array}{l}\text { Defesa Civil; Sistema } \\
\text { Penitenciário; Policiamento }\end{array}$ & 34 \\
\hline Veículos e condutores & 16 & $\begin{array}{l}\text { Transporte e Trânsito; } \\
\text { Detran; IPVA }\end{array}$ & 33 \\
\hline Comunicação, Transparência e Ouvidoria & 19 & $\begin{array}{l}\text { Transparência e controle } \\
\text { social; Ouvidorias; Fale com } \\
\text { o governo }\end{array}$ & 31 \\
\hline Finanças e Impostos & 16 & $\begin{array}{l}\text { Contas e impostos; Tributos } \\
\text { Estaduais; Isenção }\end{array}$ & 27 \\
\hline Infraestrutura e Energia & 18 & $\begin{array}{l}\text { Energia Elétrica; } \\
\text { Infraestrutura Pública; } \\
\text { Estradas e Rodovias }\end{array}$ & 25 \\
\hline Documentos e certidões & 16 & $\begin{array}{l}\text { Meus Documentos; E-Docs; } \\
\text { Atestados e Declarações }\end{array}$ & 23 \\
\hline Meio ambiente & 8 & $\begin{array}{l}\text { Meio ambiente e clima; } \\
\text { Qualidade do ar; }\end{array}$ & 22 \\
\hline
\end{tabular}




\begin{tabular}{|c|c|c|c|}
\hline & & Biodiversidade & \\
\hline Agropecuária & 16 & $\begin{array}{l}\text { Agronegócio; Reforma } \\
\text { agrária; Agricultura Familiar }\end{array}$ & 22 \\
\hline Trabalho e Emprego & 12 & $\begin{array}{l}\text { Oportunidades; Emprego; } \\
\text { Carreira }\end{array}$ & 21 \\
\hline NA (Não se Aplica) & 17 & $\begin{array}{l}\text { Utilidade pública; Patrimônio; } \\
\text { Loterias }\end{array}$ & 18 \\
\hline Habitação & 11 & $\begin{array}{l}\text { Urbanismo; Moradia; } \\
\text { Habitação Rural }\end{array}$ & 18 \\
\hline Água e saneamento & 10 & $\begin{array}{l}\text { Saneamento; Recursos } \\
\text { Hídricos; Água e Esgoto }\end{array}$ & 17 \\
\hline Turismo & 6 & $\begin{array}{l}\text { Turistas; Turismo e Lazer; } \\
\text { Controle Migratório }\end{array}$ & 16 \\
\hline Justiça & 9 & $\begin{array}{l}\text { Serviços Jurídicos; Justiça e } \\
\text { Segurança; Direitos do } \\
\text { Cidadão }\end{array}$ & 15 \\
\hline Ciência, Tecnologia e Inovação & 9 & $\begin{array}{l}\text { Inovação; Pesquisa e } \\
\text { Tecnologia; } \\
\text { Educação, Ciência e } \\
\text { Tecnologia }\end{array}$ & 14 \\
\hline Fiscalização e Controle & 9 & $\begin{array}{l}\text { Defesa Do Consumidor; } \\
\text { Vigilância Sanitária; Tribunal } \\
\text { de contas }\end{array}$ & 10 \\
\hline Previdência & 5 & $\begin{array}{l}\text { Previdência; Meus Direitos; } \\
\text { Previdência Social Do } \\
\text { Servidor }\end{array}$ & 9 \\
\hline Transporte & 7 & $\begin{array}{l}\text { Mobilidade; Transporte } \\
\text { Marítimo; Transporte } \\
\text { Ferroviário }\end{array}$ & 8 \\
\hline Tecnologia da Informação e Comunicação & 8 & $\begin{array}{l}\text { Telecomunicações; } \\
\text { Qualidade e tecnologia; } \\
\text { Inclusão Digital }\end{array}$ & 8 \\
\hline Outros & 3 & \begin{tabular}{|l|} 
Outros; Serviços sem \\
classificação; Serviços on-line
\end{tabular} & 4 \\
\hline
\end{tabular}

Para que não houvesse perda de informações, quando a nomenclatura usada nos portais apresentava um conteúdo relativo a mais de uma expressão, essa categoria era duplicada, contabilizando-se assim nas diferentes expressões em que ela se encaixa. Por exemplo, observando-se os serviços listados na categoria "Atendimento Básico" do Portal de Pernambuco, concluiu-se que eles podiam ser classificados tanto dentro da expressão "Ação Social e Cidadania", quanto dentro da expressão "Saúde".

A expressão NA ("não se aplica") apresenta o conjunto de categorias que não se encaixam nas demais expressões criadas. Já a expressão "Outros" aplica-se aos casos em que o próprio portal ou app reservava uma categoria geral para agrupar serviços não incluídos em outras categorias, como, por exemplo, a categoria "Serviços sem classificação", presente no portal do ES.

Vale ressaltar que a classificação foi realizada com base nas categorias presentes nos portais e aplicativos, não considerando de forma direta a nomenclatura dos serviços inseridos nessas categorias. 


\section{Conclusões}

A partir do levantamento feito com os portais e aplicativos de governos estaduais e do Distrito Federal, foi possível identificar uma grande variação de termos utilizados para designar categorias de serviços e a falta de adoção de um padrão para a realização dessa classificação. O presente trabalho teve como objetivo apresentar uma proposta estruturada para a classificação dos serviços públicos. Acredita-se que a taxonomia proposta permite um arranjo lógico e adoção conjunta de um vocabulário controlado, o que auxilia na utilização dos sistemas de oferta de serviços públicos.

A taxonomia foi desenvolvida para auxiliar no contexto dos serviços do governo do Estado do Ceará, mas acredita-se no seu potencial de aplicação nos serviços públicos de outros estados e outras esferas administrativas. Como resultado imediato desse trabalho, a equipe de desenvolvimento do Ceará App, aplicativo do governo do estado do Ceará, está adotando as nomenclaturas apresentadas para a organização e categorização de seus serviços. Mesmo com um conjunto diversificado de serviços oferecidos, observase que as nomenclaturas propostas se adequam às necessidades do aplicativo.

Como trabalhos futuros, pretende-se aprofundar o benchmarking dos portais e apps, incluindo-se análises de layout e apresentação de ícones ainda relacionados às categorias de serviços. Outro trabalho a ser desenvolvido é um estudo da usabilidade dos sistemas, analisando como as nomenclaturas utilizadas nos diferentes portais podem influenciar o entendimento, por parte dos cidadãos, na utilização dos serviços ofertados.

Outra frente de trabalho em andamento é uma análise dos padrões de interface e interação adotados nos portais analisados. A partir dessas análises comparativas, será possível realizar avaliações mais direcionadas, possivelmente, envolvendo usuários finais a fim de se investigar o impacto das decisões de design na experiência do cidadão com a oferta de serviços do governo.

\section{Reconhecimento}

Este trabalho é parcialmente financiado pelo projeto Governo Digital do Estado do Ceará - 04772314/2020 FUNCAP.

\section{Referências}

Barbosa, S. \& Silva, B. (2010) Interação Humano-Computador. $2^{\text {a }}$ Edição. Rio de Janeiro: Elsevier.

Brasil. (2020) Decreto n.10.332, de 28 de abril de 2020. Institui a Estratégia de Governo Digital para o período de 2020 a 2022, no âmbito dos órgãos e das entidades da administração pública federal direta, autárquica e fundacional e dá outras providências.

Brasil. (2016) Ministério do Planejamento, Orçamento e Gestão. Secretaria de Logística e Tecnologia da Informação VCGE Vocabulário de Governo Eletrônico. Brasília: MP, SLTI.

Brasil. (2018) Ministério do Planejamento, Desenvolvimento e Gestão. Estratégia de Governança Digital: Transformação Digital - cidadania e governo/ Brasília: MP.

Fischer, H., Mont'alvão, C., Rodrigues, E. S. \& Engelke, A. (2019)| Compreensibilidade em textos de e-gov: uma análise exploratória da escrita do INSS. Anais do $9^{\circ} \mathrm{CIDI}$ e $9^{\circ}$ CONGIC Sociedade Brasileira de Design da Informação - SBDI Belo Horizonte | Brasil. 
Hedden, H. (2010) The Accidental Taxonomist. Information Today, Inc.: Medford.

ISO/IEC 25010 (2011) - System and Software engineering - System and software Quality Requirements and Evaluation (SQuaRE) - System and software quality models. Switzerland.

Komninos, N. (2008). Intelligent Cities and Globalisation of Innovation Networks. New York: Routledge.

Martinez, Ana. et al. (2004) Las categorías o facetas fundamentales: una metodología para el diseño de taxonomías corporativas de sitios Web argentinos. Ci. Inf., Brasília, v.33, n.2, p.106-11, maio/ago.

Morville, Peter. (2005) Ambient Findability: what we find changes who we become. O’Reilly Media: Sebastopol.

OECD. Committee, Public Governance: Oecd recommendation on digital government strategies. 2014.

Pwc EU Services. (2019) European Taxonomy for public services. Brussels: European Commission.

Rosenfeld, Louis; Morville, Peter; Arango, Jorge. (2015) Information Architecture: for the web and beyond. O'Reilly Media: Sebastopol. 